\title{
The Effect of Film Thickness on the Structural Properties of Vacuum Evaporated Poly(3-methylthiophene) Thin Films
}

\author{
Sandip V. Kamat, ${ }^{1}$ Vijaya Puri, ${ }^{2}$ and R. K. Puri' ${ }^{1}$ \\ ${ }^{1}$ Vacuum Techniques \& Thin Film Laboratory, USIC, Shivaji University, Kolhapur, India \\ ${ }^{2}$ Department of Physics, Shivaji University, Kolhapur 416004, India \\ Correspondence should be addressed to R. K. Puri, rkp_usic@unishivaji.ac.in
}

Received 5 January 2012; Accepted 8 February 2012

Academic Editors: B. F. Senkal and K. Xu

Copyright ( 92012 Sandip V. Kamat et al. This is an open access article distributed under the Creative Commons Attribution License, which permits unrestricted use, distribution, and reproduction in any medium, provided the original work is properly cited.

\begin{abstract}
This paper reports on the structural properties of poly(3-methylthiophene) P3MeT thin films prepared by vacuum evaporation on the glass substrates. The structural and surface morphology, wettability, adhesion, and intrinsic stress of these thin films were studied for three different thicknesses. The variation of the film thickness affects the structure, surface, and mechanical properties of P3MeT thin films. Vapor chopping also strongly influences the surface morphology, surface roughness, and wettability of the thin films. It was found that there is a decrease in the intrinsic stress and (RMS) roughness, while the adhesion increases with increase in film thickness.
\end{abstract}

\section{Introduction}

Among all the $\pi$-conjugated conducting polymers, polythiophene family has emerged as one of the good candidates for the preparation of numerous electric and electronic devices, such as LED [1], photovoltaic and photoconductive devices [2], sensor applications [3] because of their good physical, chemical, and electronic properties; in addition, they show good environmental stability [4]. The conductivity of these polymers can be modified from a conducting to an insulating state by means of proper doping. The composition, morphology, and physical properties of these polymers differ depending on the method used to synthesize them [5] and references therein]. However the poor solubility of these polymers restricts their use in commercial applications, as shown in [6], even if this problem can be overcome by using 3 substituted polythiophenes, see [1]. It is already reported in [7] that the alkyl side chains are not only to enhance the ease of processing, but also to modify the electronic properties of the conjugated polymers. $\mathrm{P} 3 \mathrm{MeT}$ is one of the polymers of polythiophene family showing remarkable solid-state properties including thermochromism, electrochromism, luminescence, and photoconductivity [8]; moreover, it is soluble in many organic solvents. P3MeT can be synthesized by chemical as well as electrochemical method. The electrochemical polymerization involves electrochemical oxidation of the monomer on the electrode, which is followed by precipitation, and of the well-prepared polymer films on the substrates, but this method is limited to conducting substrates only. On the contrary, the chemical polymerization using chemical oxidant gives more yields precipitated from the reaction mixture [9], which can be used as source material for thin film deposition.

The adhesion between the film and substrate is an important parameter, which decides the reliability and lifetime of the operation of any device. The intrinsic stress observed in the thin film affects several properties of the material, which may restrict its use in commercial applications. The aim of the present work is to increase the adhesion of the film to the substrate and to reduce the intrinsic stress originated in the film. The optical properties of P3MeT thin films of $100 \mathrm{~nm}$ thickness by using vacuum evaporated have previously reported by us in [10].

The present paper reports on the structural properties of $\mathrm{P} 3 \mathrm{MeT}$ thin films prepared by vacuum evaporation; moreover, the effect of the film thickness and the vapor chopping 


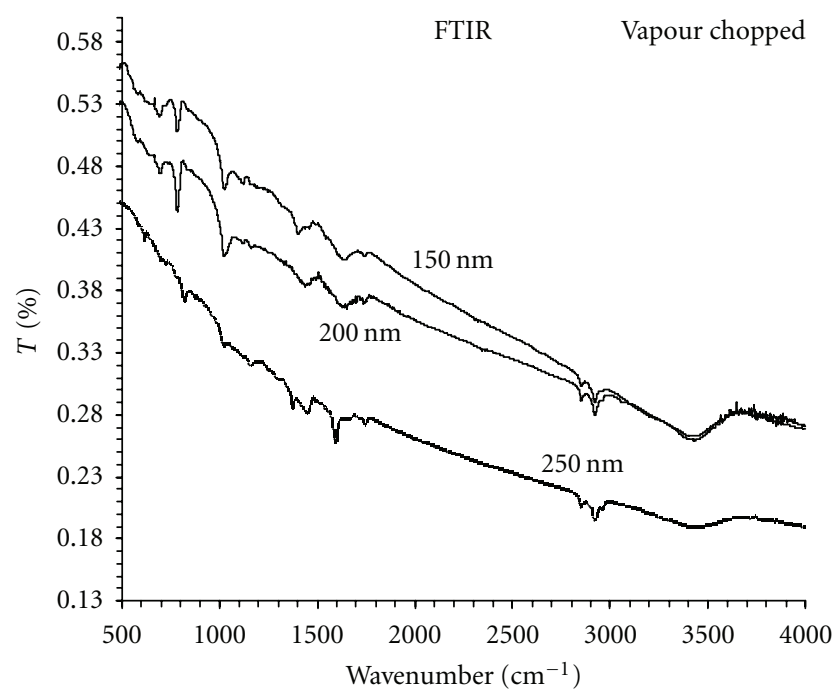

(a)

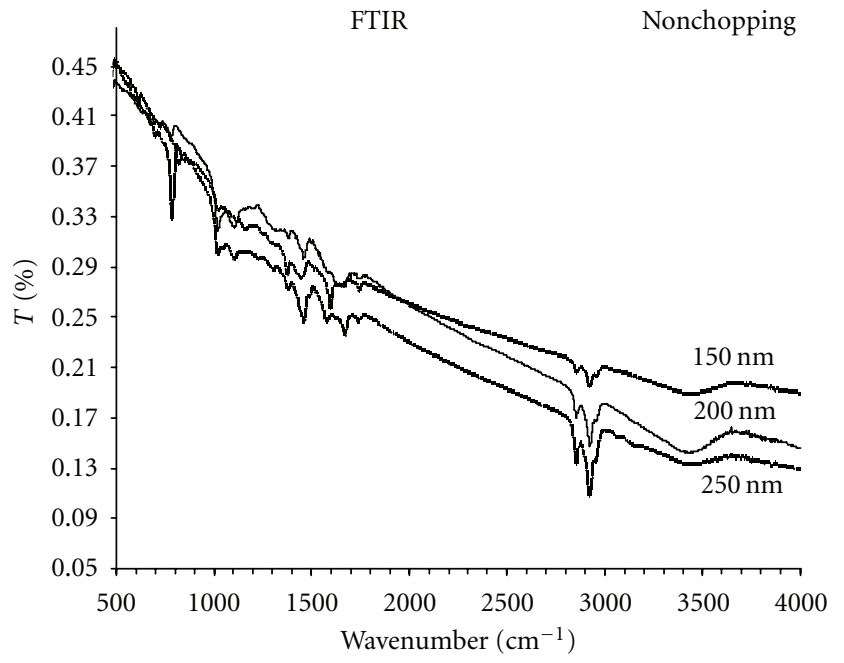

(b)

FIGURE 1: FTIR spectra of vapor-chopped and nonchopped P3MeT thin films.

technique on the of $\mathrm{P} 3 \mathrm{MeT}$ thin films surface roughness, contact angle, adhesion and intrinsic stress are being reported for the first time.

\section{Experimental}

The P3MeT powder was synthesized by an oxidation polymerization method, using iron chloride, as presented in [6]. The obtained P3MeT powder was dried under vacuum at $60^{\circ} \mathrm{C}$ for 24 hours and the P3MeT thin films were deposited using resistive heating in vacuum deposition technique at $10^{-3}$ Torr. The thickness of the P3MeT thin films was subject to change by means of varying the deposition time, and due to the vapor chopping technique, as reported in [10].

FTIR spectra of P3MeT powder and thin films were recorded by using a Perkin-Elmer's Spectrum Spectrometer in the range of $400-4000 \mathrm{~cm}^{-1}$. For FTIR, these films were scratched from glass substrate and mixed with $\mathrm{KBr}$. The Atomic Force Micrographs (AFM) were recorded using JEOL JSPM 5400 MkII Environmental Atomic Force Microscope. Thickness of the film was measured by Tolansky interferometric method. The adhesion of these thin films was meaured by direct pulloff method $[11,12]$ the accuracy of this method is $\pm 9.81 \mathrm{kgf} / \mathrm{m}^{2}$, while the intrinsic stress was calculated by using interferometric method [13]. The values of root mean square (RMS) roughness were calculated from the height values in the atomic force microscopy images using the commercial software [14].

\section{Results and Discussion}

3.1. Structural Properties. The FTIR spectra of the vapor chopped and nonchopped $\mathrm{P} 3 \mathrm{MeT}$ thin films are as shown in Figure 1. The peak at $3408 \mathrm{~cm}^{-1}$ in both types of the thin films corresponds to humidity in $\mathrm{KBr}$ [15]. The lowintensity peaks at $2926 \mathrm{~cm}^{-1}$ and $2850 \mathrm{~cm}^{-1}$ represent $\mathrm{C}-\mathrm{H}$ symmetric and $\mathrm{C}-\mathrm{H}$ asymmetric stretching, respectively. The bands at $1631 \mathrm{~cm}^{-1}$ and $1448 \mathrm{~cm}^{-1}$ in nonchopped thin films show a slight shift to $1640 \mathrm{~cm}^{-1}$ and $1446 \mathrm{~cm}^{-1}$ in the vaporchopped thin films. These bands are the $\mathrm{C}=\mathrm{C}$ symmetric and asymmetric stretching in $\mathrm{P} 3 \mathrm{MeT}$ thin films [16]. This shifting may be due to cross-linking of polymers during deposition, as stated in [17]. The range of $600-1500 \mathrm{~cm}^{-1}$ is the fingerprint region of $\mathrm{P} 3 \mathrm{MeT}$. An extra absorption band was observed in the vapor chopped films at $1156 \mathrm{~cm}^{-1}$ representing the out-of-plane deformation in $\mathrm{P} 3 \mathrm{MeT}$ thin films and the band at $1014 \mathrm{~cm}^{-1}$ and $1025 \mathrm{~cm}^{-1}$ representing the $\mathrm{C}-\mathrm{H}$ wagging. The peak at $814 \mathrm{~cm}^{-1}$ in nonchopped and at $819 \mathrm{~cm}^{-1}$ in vapor-chopped film correspond-to C-S stretching [18], whereas the peak at $604 \mathrm{~cm}^{-1}$ in nonchopped film representing C-S-C ring deformation [18] is slightly shifted to $617 \mathrm{~cm}^{-1}$ in the vapor chopped thin films.

3.2. Surface Morphology. Figure 2 shows the SEM images of $\mathrm{P} 3 \mathrm{MeT}$ thin films. It is observed that the nonchopped thin films show nonuniform deposition having high roughness. On the contrary the vapor-chopped thin films show uniform and smooth surface morphology with small grains. Nonchopped thin films consist of spherical grains [15], while in the vapor chopped thin films a clear identification of the cross-linking of polymer chain with presence of short-chain oligomers with spherical grains and smaller size can be made. An increase in the thickness causes an increase in the crosslinking of short chain polymers in the vapor-chopped thin films.

3.3. Roughness Measurement. The root mean square (RMS) roughness of the thin films was studied from 3D AFM images (see Figure 4): the RMS values were calculated from height values in the atomic force microscopy (Figure 3), as in [14]. RMS roughness is by definition the standard deviation of 


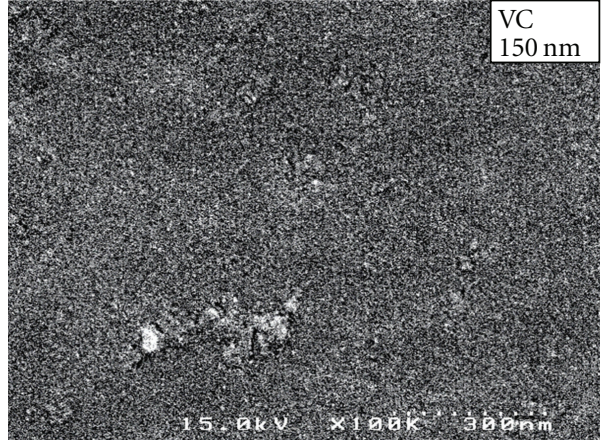

(a)

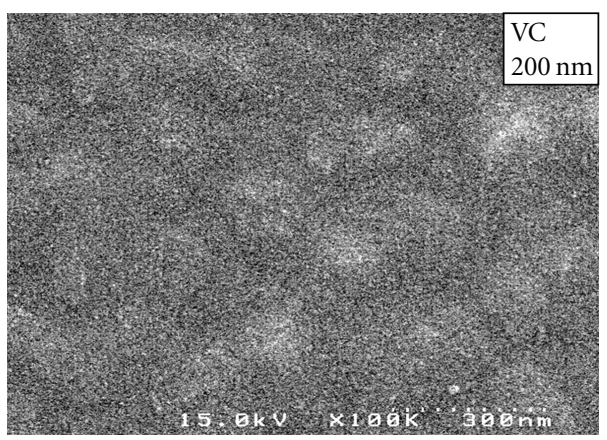

(c)

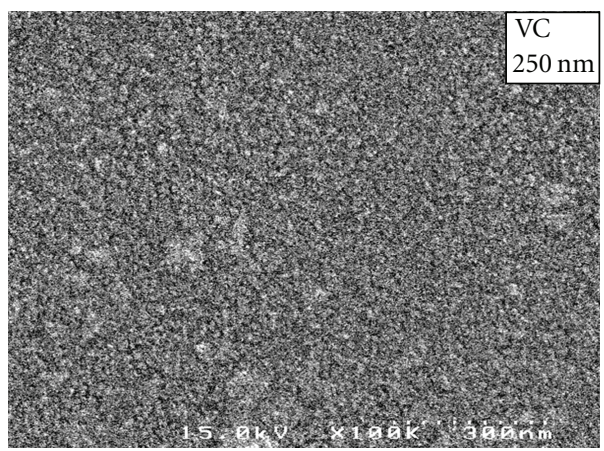

(e)

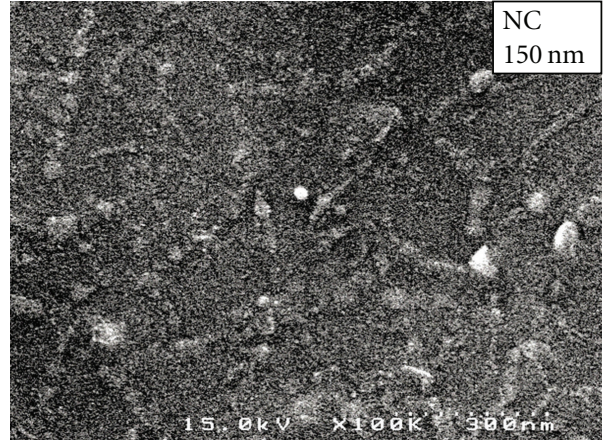

(b)

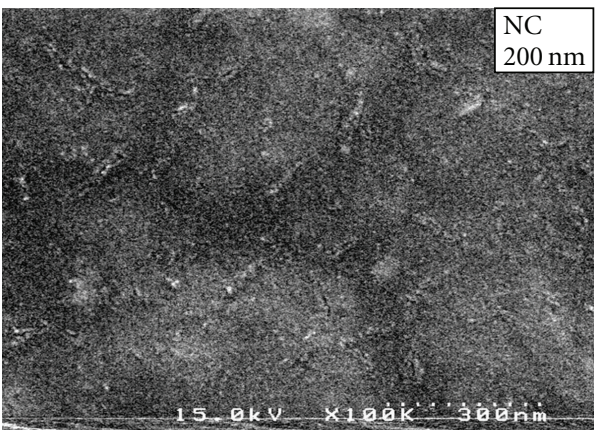

(d)

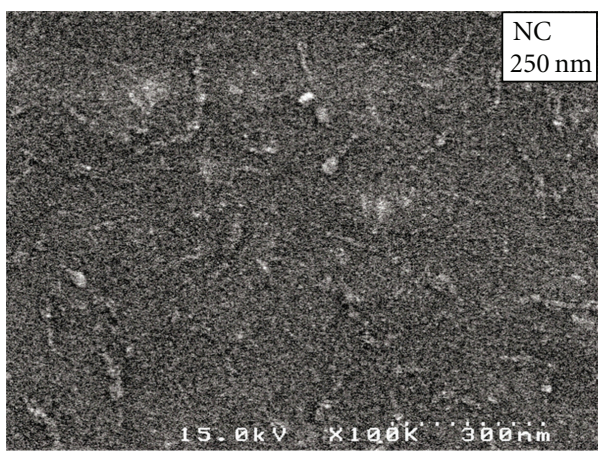

(f)

FIGURE 2: SEM images of vapor-chopped and nonchopped P3MeT thin films.

the surface height profile from the average height [19] and can be calculated using the following formula:

$$
R_{\mathrm{RMS}}=\sqrt{\frac{\sum_{i=1}^{N}\left(z_{i}-\bar{z}\right)}{N}},
$$

where $N$ is the total number of data points, $z_{i}$ is the vertical coordinate of the image, and $\bar{z}$ is the mean value of $z_{i}$.

The roughness values of vapor-chopped and nonchopped P3MeT thin films are tabulated in Table 1. It is observed that RMS roughness values decrease with an increase in the thickness of the thin film.

3.4. Wettability Test. From Figure 5, it is possible to observe that the contact angle of the nonchopped thin film is slightly greater than $90^{\circ}\left(\sim 91^{\circ}\right)$ for thickness $150 \mathrm{~nm}$ representing hydrophobic nature, which decreases due to an increase in thickness (i.e., $\left(\sim 89^{\circ}\right)$ for thickness $200 \mathrm{~nm}$ and $\left(\sim 85^{\circ}\right)$ for thickness $250 \mathrm{~nm})$ and it can also be seen that there is a decrease in the contact angle due to vapor chopping (i.e., $\left(79^{\circ}\right)$ for thickness $150 \mathrm{~nm},\left(70^{\circ}\right)$ for thickness $200 \mathrm{~nm}$ and $\left(\sim 57^{\circ}\right)$ for thickness $\left.250 \mathrm{~nm}\right)$. Vapor chopping turns the film into hydrophilic, which may be due to the reduction in the grain size and roughness as it is also evident from AFM images (Figure 4).

3.5. Adhesion. The adhesion of the thin film is measured via the Direct PullOff (DPO) method $[11,12]$ using the following formula:

$$
\sigma=\frac{g \times F}{A},
$$

where $g$ is the gravitational force, $F$ is the load (in $\mathrm{Kg}$ ), and $A$ is the area of stud. 


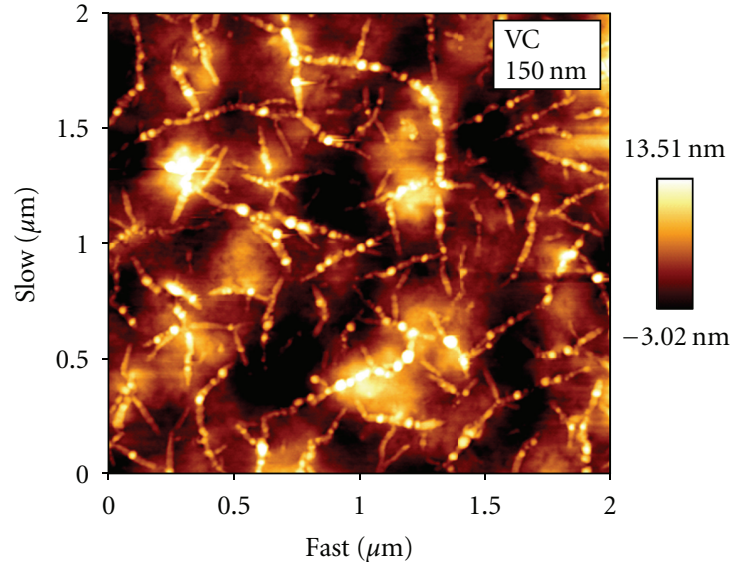

(a)

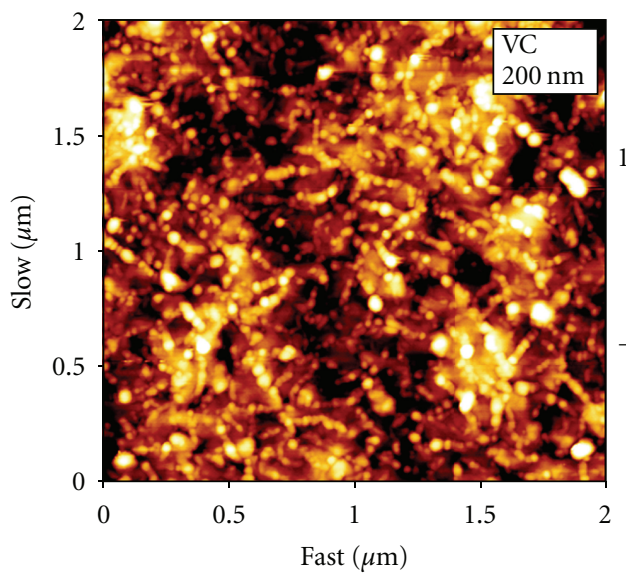

(c)

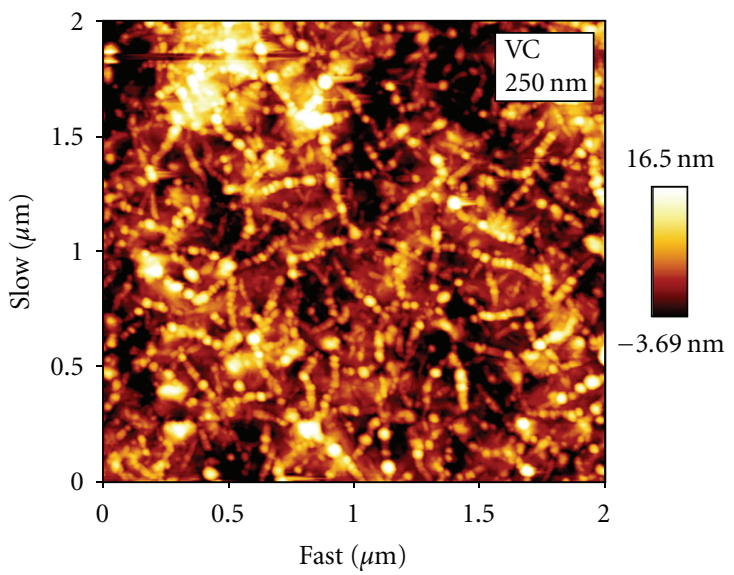

(e)

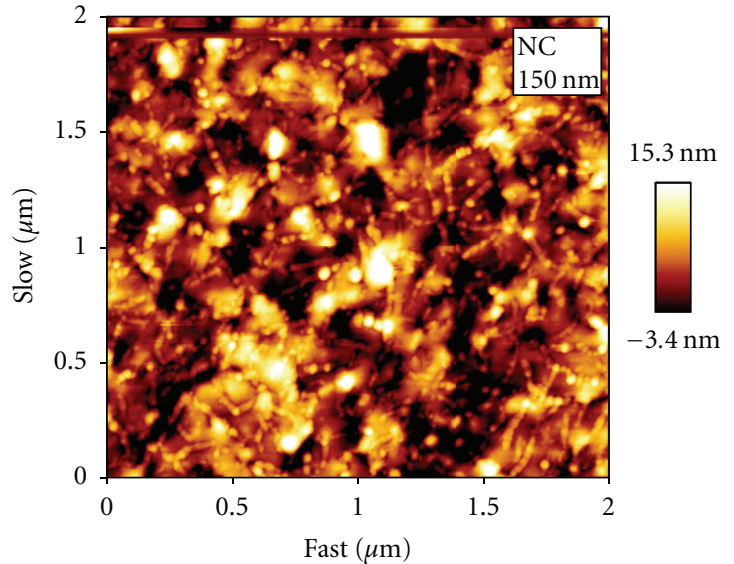

(b)

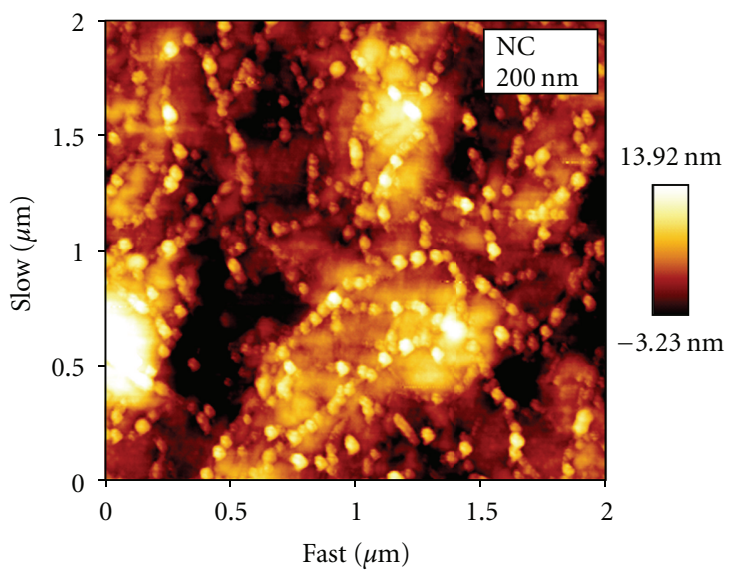

(d)

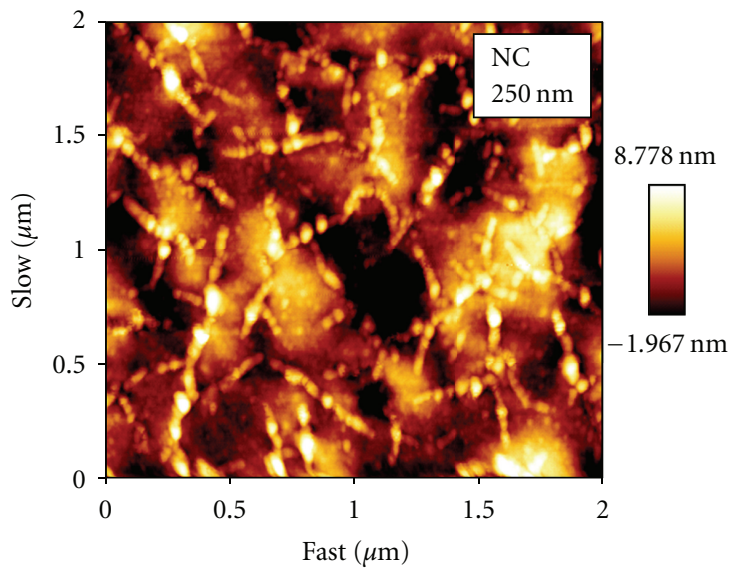

(f)

FIgURE 3: Atomic force microscopy images of vapor-chopped and nonchopped P3MeT thin films.

TABle 1: $R_{(\mathrm{RMS})}$ Roughness of the P3MeT thin films.

\begin{tabular}{lccc}
\hline Sr. no. & \multicolumn{2}{c}{ Thickness of the film in nm } & \multicolumn{2}{c}{ Root mean square (RMS) roughness (nm) } \\
Vapour chopped & 20 & 22 \\
01 & 150 & 11 & 19 \\
03 & 200 & 10.6 & 16 \\
\hline
\end{tabular}




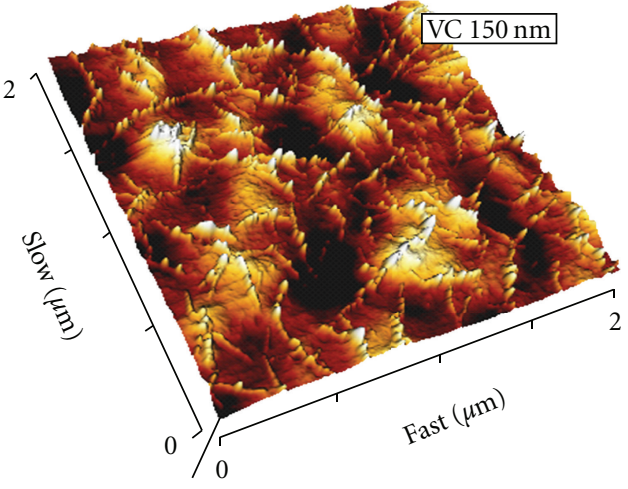

(a)

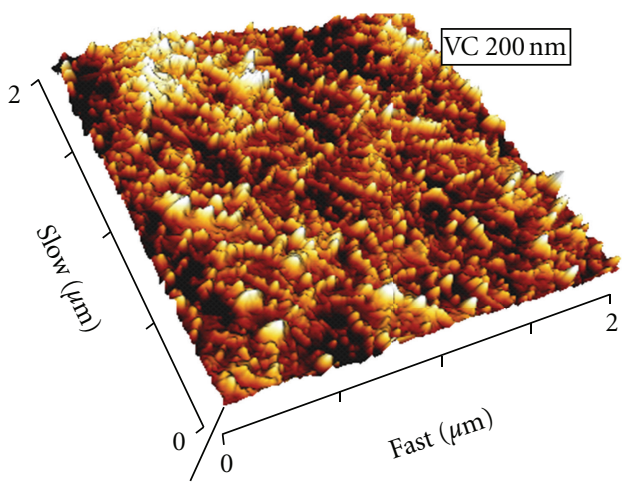

(c)

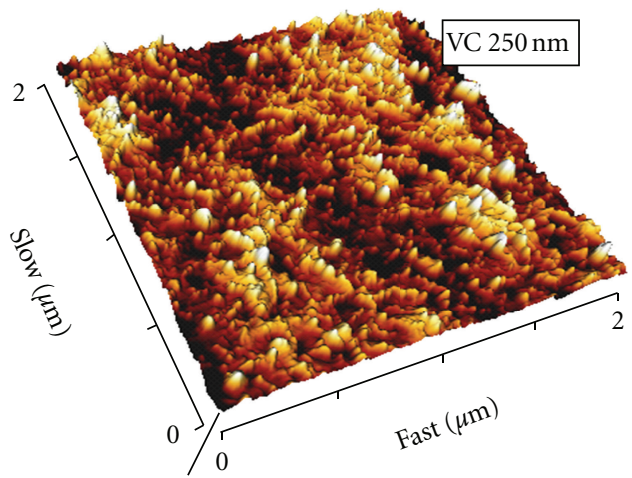

(e)

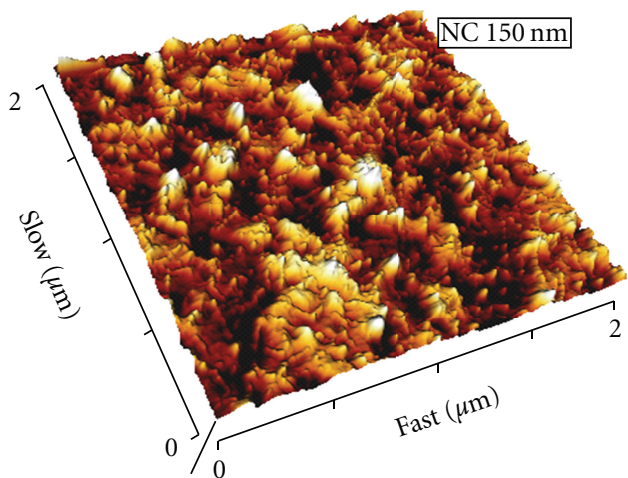

(b)

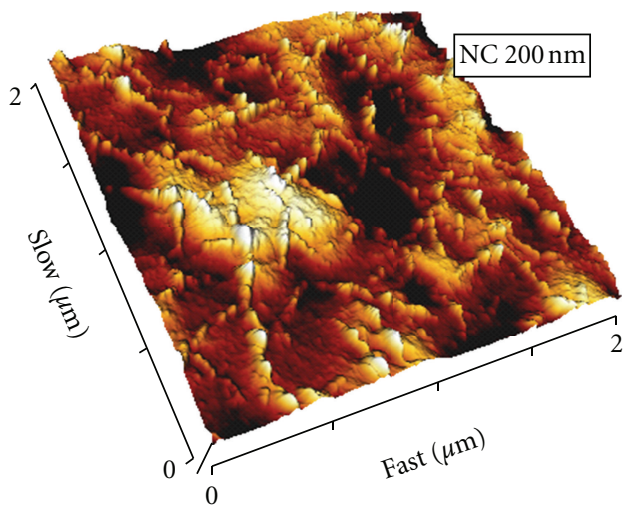

(d)

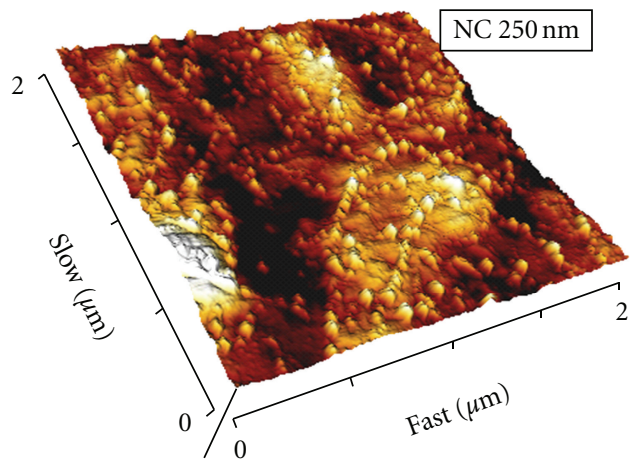

(f)

Figure 4: 3D AFM images of vapor-chopped and nonchopped P3MeT thin films.

The observed values of adhesion of vapor-chopped and nonchopped P3MeT thin films are given in Table 2. The adhesion of the film increases with an increase in the thickness of the film for both nonchopped and vapor chopped thin films. The vapor-chopped thin films show better adhesion as compared to nonchopped thin films, since the vapor chopping process changes the morphology of the film. Due to the growth flux interruption, the wetting characteristics are modified and a smaller grain size is obtained with reduced roughness (see AFM data) facilitating the production of films with minor defects and higher adhesion.
3.6. Intrinsic Stress. The intrinsic stress of thin films is measured by an interferometric method which is based on Newton's ring principle. In this method soda lime cover slips of diameter $1.9 \mathrm{~cm}$ and $0.022 \mathrm{~cm}$ thickness are used as substrates. The intrinsic stress is calculated by measuring the variation in diameter of Newton's ring before and after deposition [13]. The intrinsic stress is calculated as

$$
S=\frac{Y h^{2}\left(K_{x}-K_{y}\right)}{6 t(1-\nu)}
$$




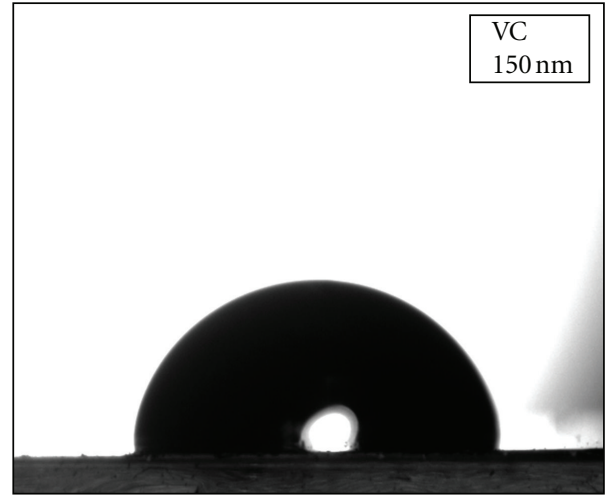

(a)

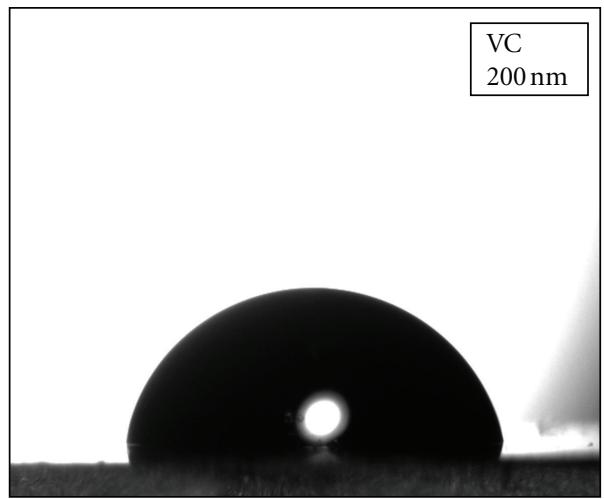

(c)

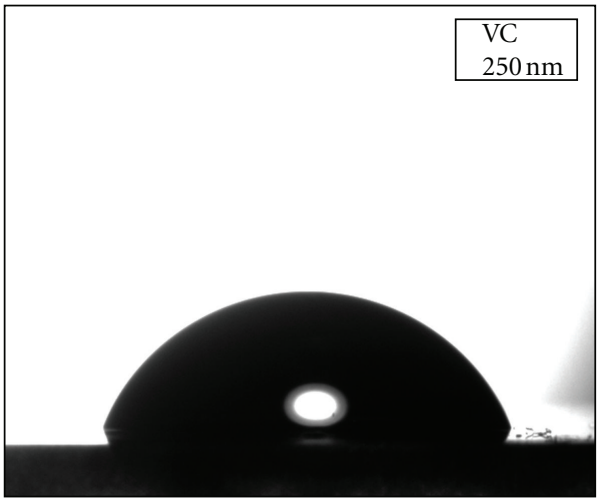

(e)

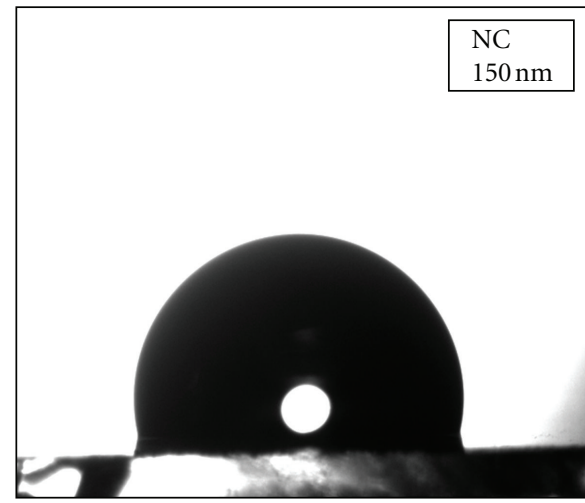

(b)

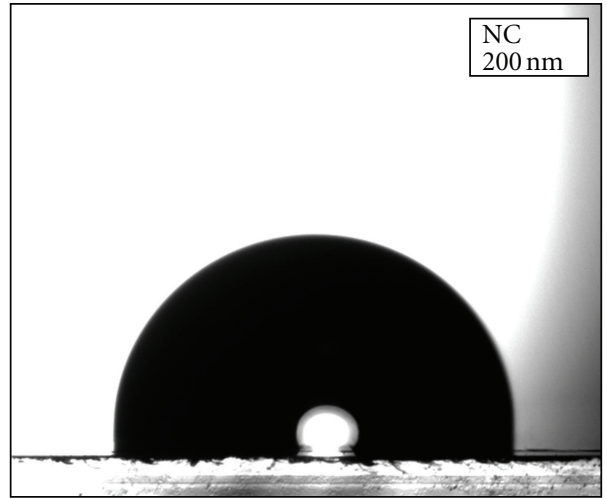

(d)

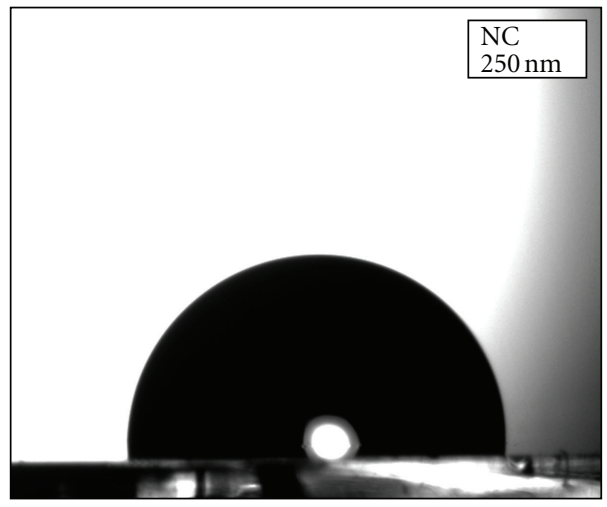

(f)

FIGURE 5: Water contact angle images vapor-chopped and nonchopped P3MeT thin films.

where $Y=2.5 \times 10^{11}$ is the Young's modulus, $v=0.178$ is the Poisson's ratio, $t$ is the film thickness. $h=0.022 \mathrm{~cm}$ is the substrate thickness, $K_{x}, K_{y}$ being the slope difference of plot $n \lambda / 2$ Vs radius Newton's ring, before and after deposition.

Figure 6 shows the variation in the intrinsic stress of the P3MeT thin film. The intrinsic stress decreases with an increase in the thickness for both nonchopped and vapor chopped thin films. The increase in the film thickness reduces the roughness of the film leading to a decrease in the intrinsic stress in the film. The vapor-chopped thin films show lower intrinsic stress than the nonchopped ones, the cross-linking of short-chain polymers (AFM data) may reduce the defects in the thin film helping to reduce the intrinsic stress in the film. The intrinsic stress observed in both films was tensile. The adhesion is closely related to intrinsic stress. As the intrinsic stress decreases, adhesion is supposed to increase, as it is also confirmed by the data presented in Table 2. Due to vapor chopping intrinsic stress relief takes place with simultaneous increase in adhesion.

\section{Conclusions}

The study on vacuum evaporated P3MeT thin films herewith presented reveals that the chopping technique increases 
TABLE 2: Adhesion and intrinsic stress of vapour-chopped and nonchopped poly(3-methyl thiophene) thin films.

\begin{tabular}{|c|c|c|c|c|c|}
\hline \multirow{2}{*}{ Sr. no. } & \multirow{2}{*}{ Thickness of the film in $\mathrm{nm}$} & \multicolumn{2}{|c|}{ Adhesion $\times 10^{2} \mathrm{~N} / \mathrm{m}^{2}$} & \multicolumn{2}{|c|}{ Intrinsic stress $\times 10^{8} \mathrm{~N} / \mathrm{m}^{2}$} \\
\hline & & Vapour chopped & Nonchopped & Vapour chopped & Nonchopped \\
\hline 1 & 150 & $117 \pm 3$ & $158 \pm 2$ & 1.132 & 1.603 \\
\hline 2 & 200 & $139 \pm 2$ & $190 \pm 3$ & 0.620 & 0.688 \\
\hline 3 & 250 & $160 \pm 3$ & $215 \pm 3$ & 0.392 & 0.5187 \\
\hline
\end{tabular}

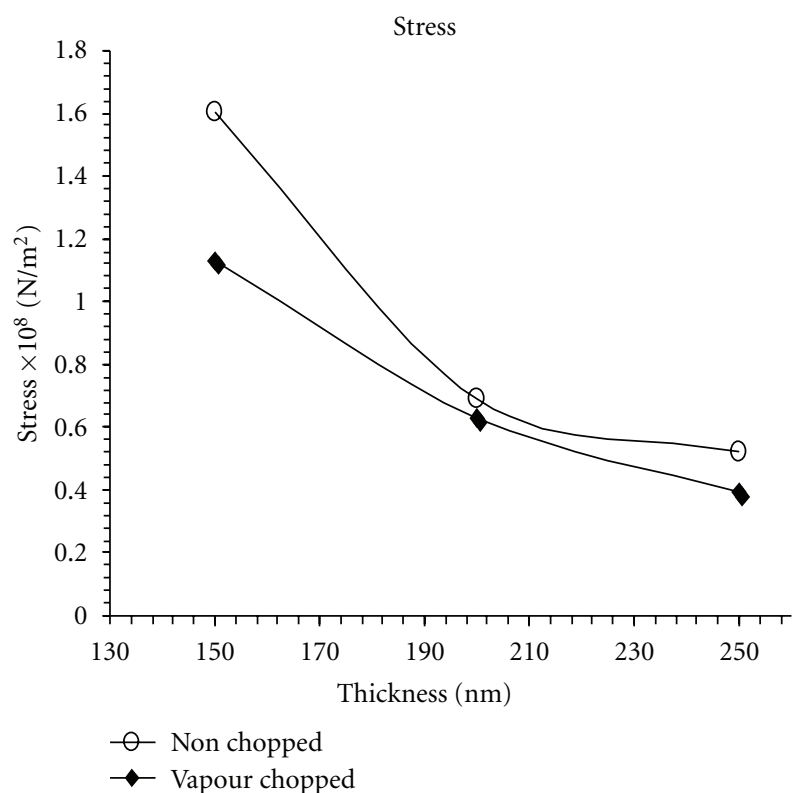

Figure 6: Intrinsic stress of vapor chopped and nonchopped P3MeT thin films.

adhesion with simultaneous reduction in intrinsic stress. It has been observed that the vapor chopping reduces the roughness of the thin film, which presents a smoother surface morphology and smaller grain size. In addition, it has been proved that by means of this technique the contact angle decreases. The increase in the thickness is responsible for the reduction in the roughness of the film, and it also ensures a higher adhesion and lower intrinsic stress. Since P3MeT thin films have a wide range of applications, a low temperature deposition technique such as vapor chopping for producing adherent coatings can prove to be significant.

\section{Acknowledgments}

The author S. V. Kamat is thankful to Council of Scientific and Industrial Research (CSIR) for the award of Senior Research Fellowship (SRF). One of the authors, V. Puri gratefully acknowledges the award of Research Scientist from University Grant Commission (UGC), India.

\section{References}

[1] S. H. Ahn, M. Z. Czae, E. R. Kim, and H. Lee, "Synthesis and characterization of soluble polythiophene derivatives containing electron-transporting moiety," Macromolucules, vol. 34, no. 8 , pp. 2522-2527, 2001.
[2] F. Bloisi, A. Cassinese, R. Papa, L. Vicari, and V. Califano, "Matrix-assisted pulsed laser evaporation of polythiophene films," Thin Solid Films, vol. 516, no. 7, pp. 1594-1598, 2008.

[3] O. Y. Posudievskii, N. V. Konoshchuk, A. L. Kukla, A. S. Pavlyuchenko, G. V. Linyuchev, and V. D. Pokhodenko, "The effect of the nature of the dopant on the sensor response of poly(3-methylthiophene) films," Theoretical and Experimental Chemistry, vol. 42, no. 6, pp. 339-345, 2006.

[4] D. H. Park, B. H. Kim, M. K. Jang, K. Y. Bae, S. J. Lee, and J. Joo, "Synthesis and characterization of polythiophene and poly (3-methylthiophene) nanotubes and nanowires," Synthetic Metals, vol. 153, no. 1-3, pp. 341-344, 2005.

[5] G. B. V. S. Lakshmi, A. Dhillon, D. K. Avasthi, A. M. Siddiqui, and M. Zulfequar, "Synthesis and characterization of thin films of poly(3-methyl thiophene) by rf-plasma polymerization," Materials Letters, vol. 64, no. 15, pp. 1672-1673, 2010.

[6] R. Daik and S. Maniam Maly, Journal of Chemical, vol. 9, pp. 16-21, 2007.

[7] G. E. Gunbas, A. Durmus, and L. Toppare, "A unique processable green polymer with a transmissive oxidized state for realization of potential RGB-based electrochromic device applications," Advanced Functional Materials, vol. 18, no. 14, pp. 2026-2030, 2008.

[8] M. Mazur, Thin Solid Films, vol. 472, no. 1-2, pp. 1-4, 2005.

[9] A. K. Narula, R. Singh, K. L. Yadav, K. B. Ravat, and S. Chandra, "Effect of synthesis temperature and doping level on conductivity and structure of poly(3-methyl thiophene)," Applied Biochemistry and Biotechnology, vol. 96, no. 1-3, pp. 109-117, 2001.

[10] S. V. Kamat, S. H. Tamboli, V. Puri, R. K. Puri, R. B. Patil, and M. F. Luo, "Determination of optical transmission loss in poly (3-methyl thiophene) thin film planar waveguide: effect of vapour chopping," Progress In Electromagnetics Research $M$, vol. 18, pp. 197-207, 2011.

[11] P. V. Patil, U. V. Nerle, R. K. Puri, and V. puri, "Adhesion improvement and intrinsic stress decrease in cerium oxide thin films by chopping," Journal of Adhesion Science and Technology, vol. 10, no. 2, pp. 151-159, 1996.

[12] R. B. Patil, R. K. Puri, and V. Puri, "Intrinsic stress of bismuth oxide thin films: effect of vapour chopping and air ageing," Journal of Physics Conference Series, vol. 114, no. 1, Article ID 012036, 2008.

[13] V. Puri and R. K. Puri, "Adhesion enhancement of thin film deposits by chopping," Japanese Journal of Applied Physics, vol. 32, no. 10, pp. 4699-4702, 1993.

[14] I. Horcas, R. Fernandez, J. M. Gomez-Rodriguezs, J. Colchero, J. Gómez-Herrero, and A. M. Baro, "A software for scanning probe microscopy and a tool for nanotechnology," Review of Scientific Instruments, vol. 78, Article ID 013705, pp. 1-8, 2007.

[15] A. D. Marani and A. A. Entezami, "New synthesis method of polythiophenes," Iranian Journal of Polymer Science \& Technology, vol. 3, no. 1, pp. 2-12, 1994. 
[16] M. R. Karim, K. T. Lim, C. J. Lee, and M. S. Lee, "A facile synthesis of polythiophene nanowires," Synthetic Metals, vol. 157, no. 22-23, pp. 1008-1012, 2007.

[17] J. B. Yadav, R. K. Puri, and V. Puri, "Improvement in mechanical and optical properties of vapour chopped vacuum evaporated PANI/PMMA composite thin film," Applied Surface Science, vol. 254, no. 5, pp. 1382-1388, 2007.

[18] A. Gok, M. Omastova, and A. G. Yavuz, "Synthesis and characterization of polythiophenes prepared in the presence of surfactants," Synthetic Metals, vol. 157, no. 1, pp. 23-29, 2007.

[19] T. Jiang, N. Hall, A. Ho, and S. Morin, "Quantitative analysis of electrodeposited tin film morphologies by atomic force microscopy," Thin Solid Films, vol. 471, no. 1-2, pp. 76-85, 2005. 

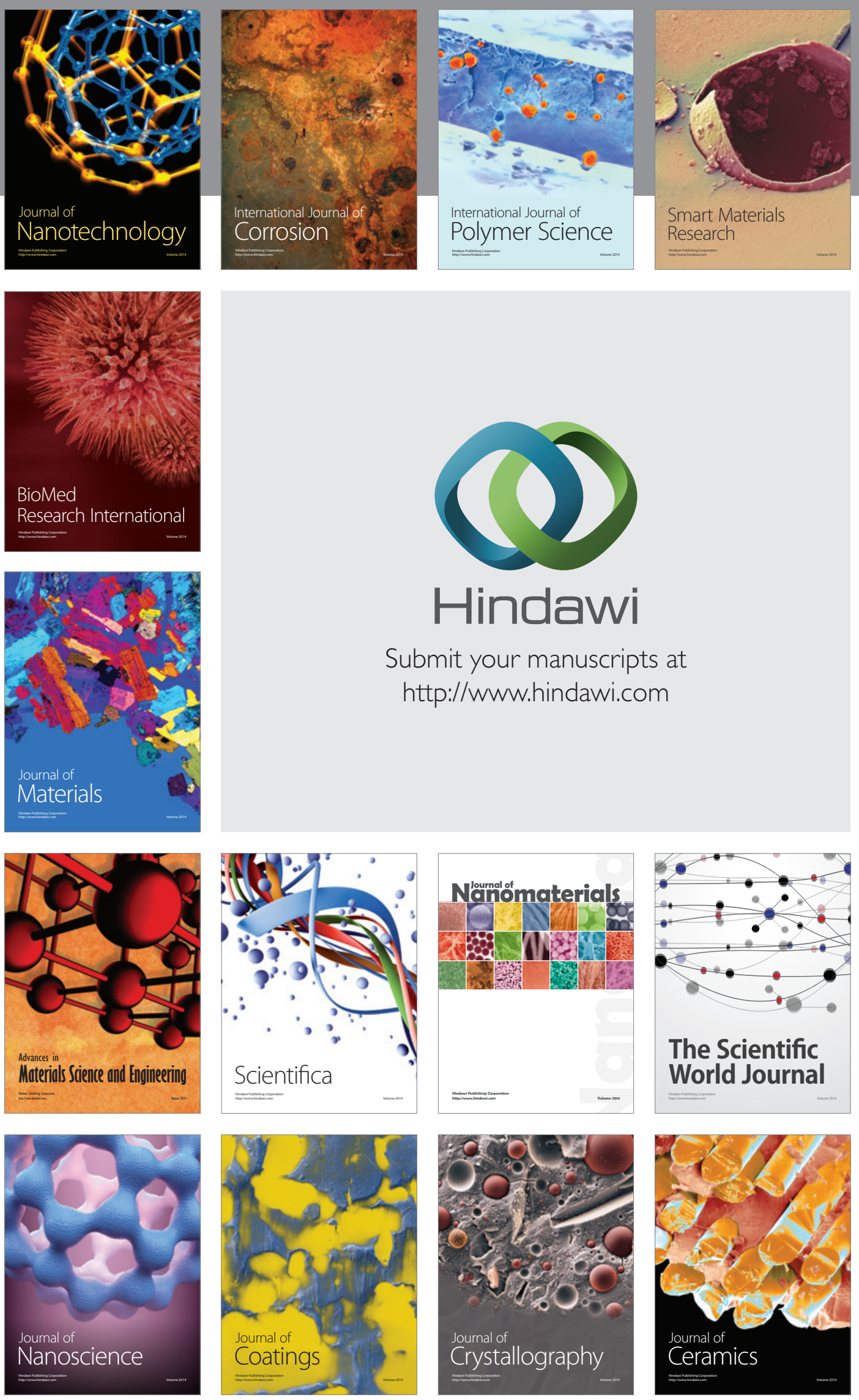

The Scientific World Journal

Submit your manuscripts at

http://www.hindawi.com

\section{World Journal}

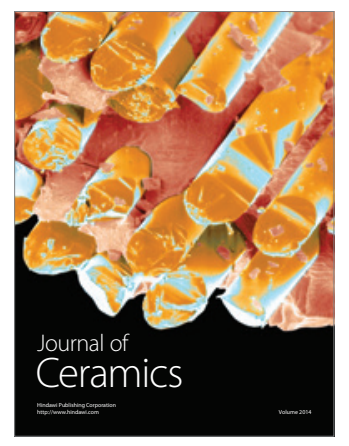

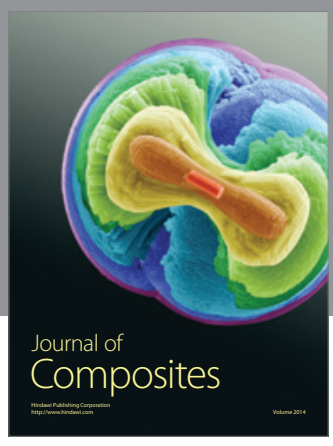
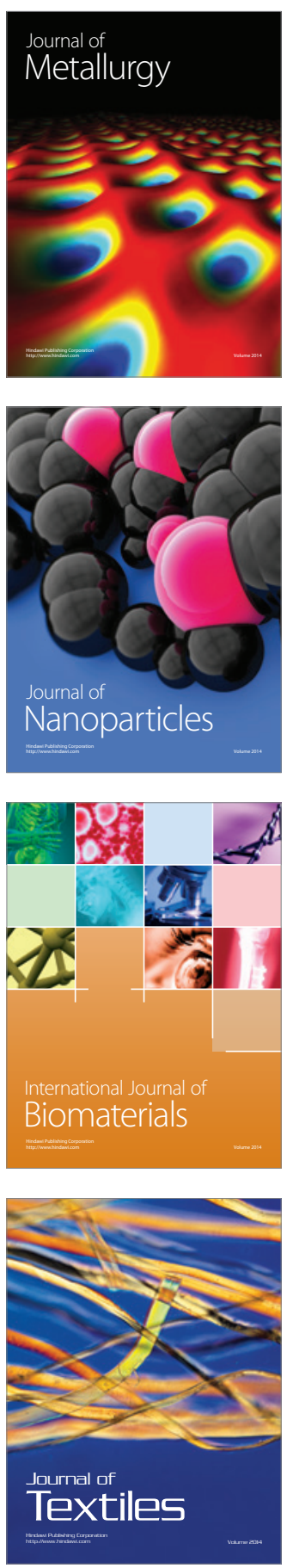